\title{
GESTÃO POR PROCESSOS: UMA CONTRIBUIÇÃO AO PROCESSO PRODUTIVO PARA INDÚSTRIA DE ESQUADRIAS
}

\author{
Eduardo Jaime Cerezer \\ Rafaela Dutra Tagliapietra ${ }^{2}$
}

\section{Resumo}

Diante das crescentes mudanças no cenário dos negócios, as empresas se deparam com a exigência de adequar o modelo de gestão organizacional, visando responder às novas condições instauradas pelo mercado. Neste sentido, o presente estudo objetiva propor um modelo de processo produtivo para indústrias de esquadrias, com a finalidade de otimizar seus resultados financeiros e econômicos. Para tanto, procedeu-se inicialmente ao mapeamento do processo produtivo de uma organização inserida no referido contexto, por meio das diretrizes propostas pela ferramenta BPM (Business Process Management). Adicionalmente, como fonte de evidências, utilizou-se a técnica de observação direta, entrevistas semiestruturadas com funcionárioschave da Marcenaria XY, organização selecionada para o estudo, além da análise documental de registros institucionais. A partir da aplicação do modelo produtivo desenvolvido neste estudo, conclui-se que, com os ajustes e melhorias propostas no fluxograma, o a Empresa estudada terá seu processo produtivo agilizado em, aproximadamente, $12 \%$ no que diz respeito ao tempo despendido para a realização das atividades e uma redução de $8,35 \%$ no custo total de sua operação. Por fim, destaca-se a relevância do estudo para a Empresa, visto que os resultados esperados foram concretizados após a proposição do novo fluxograma da produção e possibilitaram a ampliação do conhecimento acerca do seu processo produtivo, potencializando seus resultados financeiros e aumentando sua capacidade produtiva.

Palavras-chave: Processo produtivo. Gestão por processos. Estrutura de custos do processo. 


\title{
CONTRIBUTION TO THE PRODUCTION PROCESS OF INDUSTRIES OF FRAMES: THE CASE OF THE MARCENARIA XY
}

\begin{abstract}
Faced with the growing changes without a business scenario, managers are faced with a requirement to adapt to the organizational management model, aiming to respond to the new market conditions. In this sense, the present study aims to propose a production model for the window making industry, in order to optimize its financial and economic results. For BPM (Business Process Management), through process management. Additionally, as a source of evidence, the direct observation technique was used, semi-structured interviews with employees of the Marcenaria XY, organization selected for the study, as well as documentary analysis of institutional records. From the application of the produced model developed in the study, it is concluded that, with the adjustments and improvements proposed in the flowchart, the Company studied, its production process accelerated by approximately $12 \%$ with respect to the time spent for a activities and an $8,35 \%$ reduction in the total cost of its operation. Finally, the relevance of the study to the Company is highlighted, since the expected results were achieved after a proposal was made for the new production flowchart and enabled an increase in the knowledge about its production process, enhancing its financial results and increasing its productive capacity.
\end{abstract}

Keywords: Productive process. Process management. Process cost structure.

\section{Resumen}

Ante los crecientes cambios en el escenario de los negocios, las empresas se enfrentan a la exigencia de adecuar el modelo de gestión organizacional, para responder a las nuevas condiciones instauradas por el mercado. En este sentido, el presente estudio objetiva proponer un modelo de proceso productivo para industrias de escuadras, con la finalidad de optimizar sus resultados financieros y económicos. Para ello, se procedió inicialmente al mapeo del proceso productivo de una organización insertada en dicho contexto, por medio de las directrices propuestas por la herramienta BPM (Business Process Management). Adicionalmente, como fuente de evidencias, se utilizó la técnica de observación directa, entrevistas semiestructuradas con funcionarios clave de la Marcenaria XY, organización seleccionada para el estudio, además del análisis documental de registros institucionales. A partir de la aplicación del modelo productivo desarrollado en este estudio, se concluye que, con los ajustes y mejoras propuestas en el diagrama de flujo, la Empresa estudiada tendrá su proceso productivo agilizado en aproximadamente el $12 \%$ en lo que se refiere al tiempo empleado para la realización de las actividades actividades y una reducción del 
$8,35 \%$ en el costo total de su operación. Por último, se destaca la relevancia del estudio para la Empresa, ya que los resultados esperados se concretar después de la proposición del nuevo diagrama de flujo de la producción y posibilitar la ampliación del conocimiento acerca de su proceso productivo, potenciando sus resultados financieros y aumentando su capacidad productiva .

Palabras clave: Proceso productivo. Gestión por procesos. Estructura de costes del proceso.

\section{INTRODUÇÃO}

As crescentes mudanças no cenário de negócios geram a necessidade de procurar modelos de gestão que possam responder às novas condições instauradas pelo fenômeno da globalização, exigindo busca contínua pela competitividade e pela rápida adaptação (BRODBECK et al., 2016; ROSSÉS et al., 2017). Tais elementos impactam em três aspectos inerentes ao negócio, independentemente de sua natureza: a redução de custos, a redução de falhas nos processos e o aumento da produtividade organizacional. Diante desse contexto, faz-se necessário reavaliar e adequar esses fatores à nova realidade instaurada.

Para tanto, a organização deve munir-se de estratégias coerentes com o valor que pretende gerar ao cliente, sem se esquecer de sua incansável busca pela competitividade, partindo da compreensão mais profunda do negócio para, posteriormente, traçar mudanças estratégicas e profundas na organização. Com a finalidade de ampliar o entendimento acerca das causas-efeitos e tomar as decisões mais assertivas, faz-se necessário desvendar quais processos são essenciais para a organização. Nessa perspectiva, a empresa pode recorrer à gestão por processos, ferramenta considerada ideal para a gestão dessa mudança de visão organizacional (BARNETT, 2003).

Capote (2012), em seu livro "BPM (Business Process Management) Para Todos", traz uma nova perspectiva para visualizar o negócio de maneira holística. Segundo o autor, o BPM, enquanto abordagem disciplinar, identifica, desenha, executa, documenta, mensura, monitora, controla e melhora os processos de negócio, a fim de alcançar resultados consistentes e coerentes com as estratégias adotadas pela organização. Assim, constata-se que essa abordagem é ideal para compreender melhor o negócio, descrever e identificar os processos que contribuem, ou não, com a atividade fim da organização e gerar ganhos de eficiência, tanto no que diz respeito aos custos, quanto no que tange a produtividade organizacional. Corrobora essa afirmação as conclusões descritas por Santis et al. (2012), em seu estudo, onde relatam que a aplicação da abordagem do BPM colabora com a padronização dos processos, facilita o 
desenvolvimento do fluxo de atividades, organização das rotinas, redução de custos e evita desperdícios.

Desse modo, surge a seguinte problemática de pesquisa: Qual o modelo produtivo mais adequado às indústrias de esquadrias, visando maximizar ganhos e minimizar perdas? Assim, o presente trabalho propõe-se a propor um modelo produtivo adequado a empresas do setor de esquadrias, visando otimizar seus resultados financeiros e econômicos. Para tanto, o objetivo geral foi desdobrado nos seguintes objetivos específicos: a) Mapear o atual processo produtivo da Marcenaria XY; b) Desenvolver um modelo matemático que mensure os custos operacionais de cada tarefa do processo produtivo; c) Propor as melhorias necessárias para a adequação do processo produtivo à realidade da Empresa.

\section{REFERENCIAL TEÓRICO}

\subsection{PROCESSOS DE NEGÓCIOS}

Para Hammer e Champy (1995, p. 24), processos são denominados como sendo "um conjunto de atividades com uma ou mais espécies de entrada e que criam uma saída de valor para o cliente”. Na visão de Ould (2005), os processos de uma organização podem ser compreendidos como atividades, tarefas e/ou etapas que são abastecidos por insumos e geram produtos específicos. Nessa mesma perspectiva, Villela (2000) resume os componentes dos processos em: inputs, outputs, tempo, espaço, ordenação, objetivos e valores que, quando interligados logicamente, irão resultar em uma estrutura para fornecer produtos ou serviços ao cliente. Sua compreensão é essencial, pois é o segredo para o sucesso do negócio, segundo o autor.

Dada a importância dos processos para a gestão de uma organização, Adair e Murray (1996) constataram que os processos evoluem ao longo do tempo, ou seja, cada processo possui seu ciclo de vida pré-estabelecido, o qual está esquematizado, segundo a visão dos autores, na Figura 1.

Figura 1 - Ciclo de vida de um processo 


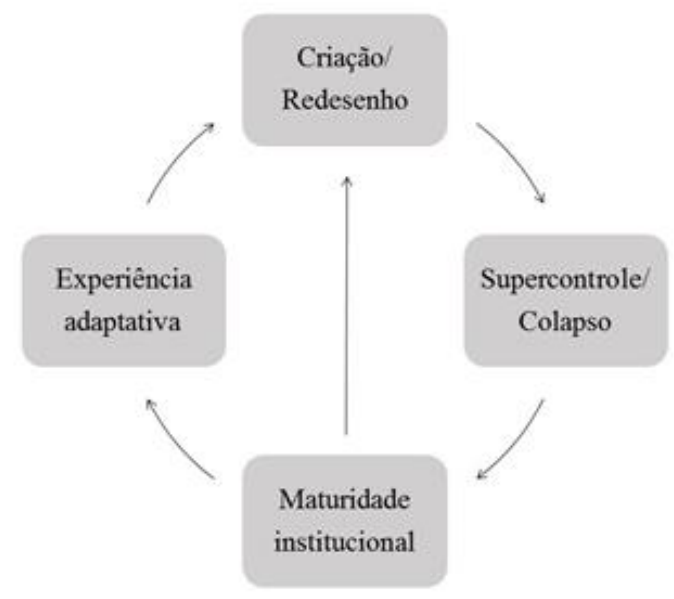

Fonte: adaptado de Adair e Murray (1996)

Além do ciclo de vida, os processos possuem outras características importantes de serem observadas, como é o caso de sua classificação. Cerqueira Neto (1994) classifica os processos em três categorias, sendo eles, os processos primários, os quais tocam o cliente diretamente e, em caso de qualquer falha, a identificação por parte do cliente é imediata; os processos de apoio, ou seja, aqueles que colaboram com os processos primários na obtenção do sucesso junto aos clientes e; por fim, os processos gerenciais, os quais existem para controlar as atividades de apoio e os processos primários.

\subsection{GESTÃO POR PROCESSOS}

Com base nas definições de processos organizacionais ou de negócios, parte-se ao entendimento da concepção de gestão por processos (GP). A GP baliza-se a partir da visão sistêmica de gerir os processos essenciais contemplados na cadeia de valor da organização de forma integrada (BRODBECK et al., 2016). Assim, busca atender as demandas dos stakeholders da organização, no que tange ao tempo, custo e qualidade desejados (SMART et al., 2009; ALBUQUERQUE; ROCHA, 2006). A partir dessa perspectiva, entende-se como benefício relevante da GP a redução de custos, a ampliação da produtividade, no que diz respeito à eficiência produtiva da organização e a agilidade, no que tange a rapidez das mudanças organizacionais (DIXON, 2012).

De acordo com Brodbeck et al. (2016), a fim de que a GP seja implementada técnicas e métodos de gestão, ferramentas e tecnologias devem ser adicionados às rotinas da organização. Tal ação tem o objetivo de integrar os processos, as pessoas e os 
sistemas existentes no contexto das empresas, permitindo a integração e o compartilhamento de informações, bem como o acompanhamento dos processos da cadeia de valor do negócio, fornecendo um direcionamento estratégico único para a organização (DIXON, 2012).

Nesse sentido, o entendimento acerca da metodologia BPM, proposto por Brodbeck et al. (2016), adequa-se plenamente ao escopo deste estudo, pois "contempla a identificação, modelagem e o gerenciamento de processos, integrando pessoas, atividades e sistemas, sendo um dos instrumentos para operacionalizar a GP”. Além disso, na visão de Debevoise (2005), o BPM possibilita mudanças nos processos empresariais, a partir do gerenciamento centrado no cliente e de seu objetivo principal, o qual consiste em acompanhar, mensurar e melhorar os processos da organização. Por fim, destaca-se que gerenciar uma organização em função de seus processos essenciais constitui-se objetivo de longo prazo, projetando cultura participativa de mudança (LEE; DALE, 1998). Em função do referido aspecto a BPM é relevante para organizações que devem se adaptar constantemente devido ao fenômeno da globalização.

\section{PROCEDIMENTOS METODOLÓGICOS}

O presente estudo classifica-se como de natureza descritiva que, segundo Gil (2002, p. 42), “tem como objetivo primordial a descrição das características de determinada população ou fenômeno ou, então, o estabelecimento de relações entre variáveis". Além disso, com o intuito de atingir os objetivos propostos no trabalho, realizou-se um estudo de natureza qualitativa que, segundo Richardson (1999), caracterizam-se como método adequado para compreender, em profundidade, um fenômeno social. Roesch (1996), salienta ainda, que o emprego da pesquisa qualitativa é conveniente quando se trata de melhorar a efetividade ou selecionar metas e constituir uma intervenção em um programa ou plano.

A partir da identificação da natureza atribuída à pesquisa, determina-se o tipo de pesquisa que será utilizado para desenvolver o estudo. No presente trabalho, utilizou-se o estudo de caso, que segundo Yin (2005), é uma estratégia de pesquisa que aprofunda o conhecimento pré-estabelecido de fenômenos individuais, organizacionais, sociais, políticos e de grupos, entre outros. Além disso, o autor afirma que o estudo de caso permite ao pesquisador focar no "caso" e reter uma perspectiva holística, como no estudo de processos organizacionais e administrativos (YIN, 2005), encaixando-se perfeitamente aos objetivos traçados para este estudo. 


\subsection{LOCUS DA PESQUISA}

A marcenaria estudada encontra-se localizada na região central do RS. A Empresa atua no ramo industrial há mais de 30 anos, dedicando-se à produção de esquadrias em madeira. O portfólio de produtos oferecidos pela organização a ser estudada pode ser subdividido nos seguintes produtos: 1) Janela Veneziana; 2) Janela Max-air; 3) Janela de Correr; 4) Portas (internas e externas); 5) Porta para Garagem; 6) Revestimentos; e 7) Rodapé.

Fundada em 1985, a Marcenaria XY possui atualmente sete funcionários, sendo desses três marceneiros, dois auxiliares de marceneiro, um encarregado dos serviços gerais e um funcionário responsável pelo setor administrativo. Organização de cunho familiar classifica-se como empresa de pequeno porte, de acordo com a legislação de Lei Complementar $\mathrm{N}^{\circ} 123$, de 14 de Dezembro de 2006.

\subsection{BPM (BUSINESS PROCESS MANAGEMENT)}

Segundo Capote (2012), a vida cotidiana se resume no somatório de inúmeros processos, conscientes ou inconscientes. Quando se adquire uma mercadoria em um site ou quando se contrata um serviço específico, não está sendo apenas consumido o produto e/ou serviço, mas participando da produção desses, ou seja, as pessoas tornamse corresponsáveis com seus resultados. Assim, sem o desenvolvimento, controle e aperfeiçoamento contínuo de processos, a vida seria caótica, bem como uma organização sem o adequado gerenciamento de seus processos (CAPOTE, 2012).

A partir dessa constatação, faz-se necessário que os processos de negócio sejam descritos e, posteriormente, acompanhados a fim de tornar a gestão da organização mais eficiente. Diante dessa perspectiva, verificam-se diferentes ferramentas que, quando bem aplicadas, auxiliam no gerenciamento dos processos, os quais impactarão no resultado final da organização, como é o caso do BPM (Business Process Management).

Assim, o BPM vai além do que poderia ser uma disciplina de gestão, é uma mudança de mentalidade. Para o BPM, o mais importante é a entrega de valor ao cliente e reconhece como grande barreira organizacional o entendimento claro das reais necessidades do cliente, ou seja, o que esse verdadeiramente valoriza, enquanto produto/serviço. Além disso, a metodologia tem o intuito de alcançar a "tríplice coroa" organizacional: 1) Redução de custos; e 2) Melhorar o relacionamento com o cliente; resultando na 3) Excelência operacional. 
Os primeiros passos para a utilização do BPM em organizações iniciantes, segundo Capote (2012), podem ser definidos como dez itens. O primeiro passo do BPM consiste em levantar o número de processos que a organização realmente possui, buscando compreender a conexão entre os processos, a cadeia de valor e os objetivos que os objetivos de negócio da empresa.

O segundo passo do BPM objetiva descrever os processos na situação em que eles se encontram atualmente, possibilitando uma análise inicial desses. Diante dessa perspectiva, o mais importante é descrever os processos de forma clara e objetiva, tanto na forma de diagramas, quanto na descrição textual complementar sobre os principais pontos.

O terceiro passo do BPM, tem a finalidade de questionar qual o objetivo de cada processo e descobrir qual é o real sentido desse em relação aos objetivos de negócio da empresa. Executado esse passo, a organização compreenderá a colaboração de cada processo para entregar de valor ao cliente.

O quarto passo consiste em identificar e agrupar os processos em três diferentes classificações: primários, de apoio e de gestão. Nesse ponto, a organização terá um maior conhecimento sobre a situação em que se encontra.

No quinto passo do BPM é realizado um levantamento de informações sobre os processos de negócios identificados e verificar se a estratégia adotada até o momento é coerente com os principais processos da organização. Esse levantamento proporcionará a análise, revisão e adequação das estratégias utilizadas pela empresa, com a finalidade de adequá-las aos processos de negócio.

O sexto passo do BPM busca definir quais são os processos que serão analisados, pois com o resultado da análise em mãos, a organização poderá traças estratégias consistentes com os processos de negócio da empresa. Vale destacar, que no momento em que a organização conhece realmente seus processos, saberá quais deles auxiliam, ou não, na entrega de valor ao cliente.

No sétimo passo, os processos escolhidos são analisados detalhadamente, com o auxílio de todos os envolvidos com o processo em questão, através de entrevistas e workshops, por exemplo. O autor ressalta, que nessa etapa, deve-se procurar descobrir os tempos e os recursos necessários para a realização de cada atividade do processo, bem como os pontos falhos inerentes ao processo.

O oitavo passo consiste na preparação de um material de divulgação das informações e resultados obtidos nos passos anteriores. Alguns temas interessantes de 
serem abordados nessa divulgação são: as atividades que consomem mais recursos, os recursos mais utilizados no processo, o tempo total dos processos, a capacidade efetiva de entrega de cada processo e a ligação entre os resultados de cada processo.

No nono passo do BPM, estamos na etapa de Desenho do Processos, isto é, com base nos resultados das análises, definir como o processo será executado, quais serão as atividades, os participantes, as regras, os caminhos, suas dependências e demais informações essenciais.

Por fim, no décimo passo do BPM, ocorre a operacionalização dos novos processos desenhados. Vale destacar, que esse último passo depende de dois fatores essenciais para seu efetivo funcionamento: as pessoas e as tecnologias envolvidas. Além desses, existem outros aspectos importantes de serem observados para o bom desenvolvimento da última etapa, são eles: vontade política, envolvimento das pessoas, gestão do projeto de implementação, acompanhamento e feedback e disposição para correr riscos.

\subsection{FONTES DE EVIDÊNCIAS}

Este trabalho utilizou múltiplas fontes de coleta de dados, com a finalidade de atingir os objetivos propostos de maneira concreta, são elas: a) Pesquisa Documental, por meio da análise de registros institucionais pertinentes ao estudo; b) Entrevistas Semiestruturadas, realizadas com funcionários responsáveis por atividades importantes do processo produtivo, os quais tiveram a oportunidade de apontar falhas e sugerir alterações na produção; e c) Observação Direta, por meio do acompanhamento da execução do processo produtivo.

\section{ANÁLISE DOS DADOS}

Visando responder aos objetivos fixados, optou-se por utilizar as diretrizes da ferramenta BPM. Para tanto, primeiramente, realizaram-se observações diretas do processo produtivo da Empresa em seu estágio atual. Nessa etapa foram registrados, no software de análise de dados Microsoft Excel 2010, aspectos inerentes ao desenvolvimento da produção como: a atividade, a data de realização, os horários de início e término da tarefa, o responsável e o maquinário necessários para sua execução. Em seguida, essas informações foram transferidas para fluxogramas, no software de elaboração de fluxogramas Microsoft Visio 2010, a fim de simular o fluxo do processo produtivo mapeado. 


\subsection{DESENVOLVIMENTO DO MODELO MATEMÁTICO}

Com o objetivo de quantificar o resultado econômico e financeiro do modelo produtivo desenvolvido neste estudo, buscou-se, primeiramente, desenvolver um modelo matemático capaz de mensurar os custos operacionais de cada atividade inerente ao processo produtivo em questão. $\mathrm{O}$ referido modelo foi elaborado com o intuito de formar um Índice de Custo (IC) para cada atividade do processo produtivo, visando responder o objetivo específico de "Construir um modelo matemático que mensure os custos operacionais de cada tarefa do processo produtivo" fixado para o estudo.

Cabe ressaltar que os referidos custos serão segregados por hora de trabalho, a fim de colocar todos os custos envolvidos na equação diante da mesma base de cálculo. Além disso, destaca-se que todos os índices citados no Quadro 1 foram desenvolvidos com base na literatura da área.

Quadro 1 - Índices da Estrutura de Custos

\begin{tabular}{|c|c|c|}
\hline Índice & Equação empregada & Análise do índice \\
\hline $\begin{array}{l}\text { Índice de Custo da } \\
\text { Atividade (ICA) }\end{array}$ & $\begin{array}{l}\quad \text { ICA }=(\mathrm{CC}+\mathrm{CMO}+\mathrm{CF}) \\
\text { ICA = Índice de Custo da Atividade; } \\
\mathrm{CC}=\text { Custo do Capital Empregado; } \\
\mathrm{CMO}=\text { Custo da Mão de Obra; } \\
\text { CF = Custo Fixo. }\end{array}$ & $\begin{array}{l}\text { A partir do cálculo apresentado é } \\
\text { possível encontrar o custo } \\
\text { individual de cada uma das } \\
\text { atividades presentes no processo } \\
\text { produtivo. }\end{array}$ \\
\hline $\begin{array}{l}\text { Índice de Custo por } \\
\text { Setor (ICS) }\end{array}$ & 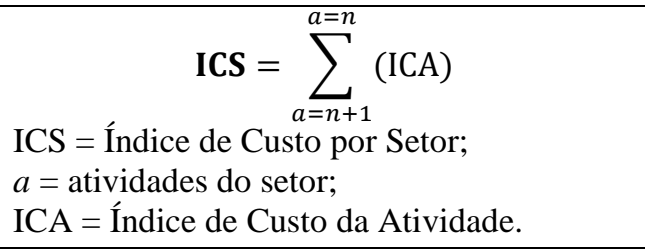 & $\begin{array}{l}\text { A análise do ICS possibilita } \\
\text { detectar o montante de custo de } \\
\text { cada setor do processo } \\
\text { produtivo, fornecendo uma visão } \\
\text { mais global e eficaz de possíveis } \\
\text { gaps no processo. }\end{array}$ \\
\hline $\begin{array}{l}\text { Índice de Custo Total } \\
\text { (ICT) }\end{array}$ & $\begin{array}{l}\qquad \text { ICT }=\sum(\text { ICS }) \\
\text { ICT }=\text { Índice de Custo Total; } \\
\text { ICS = Índice de Custo por Setor. }\end{array}$ & $\begin{array}{l}\text { A partir da análise do ICT é } \\
\text { possível fazer um diagnóstico do } \\
\text { processo como um todo e ter } \\
\text { uma visão geral de sua situação. }\end{array}$ \\
\hline $\begin{array}{c}\text { Produtividade } \\
\text { Marginal (PMgL) }\end{array}$ & $\begin{array}{l}\qquad \operatorname{PMgL}=\frac{\Delta \mathrm{Q}}{\Delta \mathrm{L}} \\
\mathrm{K}(\text { Capital })=\text { constante; } \\
\mathrm{Q} \text { (Quantidade de Obras Produzida })= \\
\text { variável; } \\
\mathrm{L}(\text { Horas trabalhadas })=\text { variável. }\end{array}$ & $\begin{array}{l}\text { Por meio do cálculo do PMgL é } \\
\text { possível verificar quanto se } \\
\text { consegue produzir a mais com o } \\
\text { acréscimo de uma unidade do } \\
\text { fator variável. }\end{array}$ \\
\hline
\end{tabular}

Fonte: elaborado pelos autores 


\subsubsection{COMPONENTES DO MODELO MATEMÁTICO DA MARCENARIA XY}

A seguir, será explicado e detalhado o cálculo dos componentes utilizados no modelo matemático desenvolvido para o processo produtivo da Marcenaria XY, o qual visa definir os custos operacionais.

\subsubsection{CUSTO DO CAPITAL EMPREGADO}

Com o intuito de precificar o custo do capital investido inerente ao processo produtivo da Marcenaria XY, analisou-se o cenário de seu quadro de máquinas (totalizando 17 equipamentos no valor de $\mathrm{R} \$ 240.000,00$ ) e do pavilhão (medindo 850 $\mathrm{m}^{2}$ e somando um montante de $\left.\mathrm{R} \$ 255.000,00\right)$ utilizado para execução das atividades. Somando-se os montantes referidos, conclui-se que o capital investido na empresa totaliza R \$ 495.000,00. Objetivando encontrar um valor médio por hora trabalhada, empregou-se sobre o valor total do capital investido uma depreciação de 10 anos. Então, chegou-se a um valor médio de $\mathrm{R} \$ 0,30$ para cada hora trabalhada.

Vale ressaltar que, considerou-se o fato da Empresa atuar há mais de 30 anos nesse setor de atividade industrial, várias máquinas que hoje fazem parte da linha de produção já estão com seu valor de depreciação igual a zero. Além disso, as máquinas adquiridas recentemente representam um valor irrisório, quando considerado o tempo de trabalho do equipamento relacionado à produção da obra.

\subsubsection{CUSTO DE OPORTUNIDADE DO CAPITAL}

Visando abarcar todas as variáveis que promovem impacto no modelo desenvolvido, ponderou-se a possibilidade de aplicação em poupança do montante total de Capital Investido encontrado para a Marcenaria XY, ao invés de ser empregado na operação da Empresa. Para tanto, considerando-se uma aplicação em poupança (livre de risco), a um valor presente de $\mathrm{R} \$ 495.000,00$, a juros de $0,5 \%$ ao mês, por um período de 12 meses. Diante desse cenário, verificou-se que seu rendimento, no final do período, seria de $\mathrm{R} \$ 2.978,18$. A partir do valor encontrado, constatou-se que a operação da Marcenaria, durante o mesmo período considerado, é superior à possibilidade de aplicação.

\subsubsection{CUSTO DA MÃO DE OBRA}

A mão de obra é um custo fixo da Marcenaria XY, porém, neste modelo matemático, o referido custo será considerado fora da base do cálculo do custo fixo. 
Essa convenção ocorre, pois se pretende mensurar a produtividade e os pontos de ociosidade de cada atividade do processo produtivo. Neste caso, torna-se necessário fazer o rateio dos custos de cada atividade através do custo da mão de obra por funcionário (uma vez que os funcionários possuem remunerações diferentes) e pelo tempo de trabalho efetivo de cada um. Visando precificar a mão de obra, detalhou-se separadamente cada etapa da produção, contendo o número de colaboradores e o tempo despendido para a realização da atividade.

Quadro 2 - Cálculo do Custo/Hora por Colaborador

\begin{tabular}{|c|c|c|}
\hline \multicolumn{2}{|c|}{ REMUNERAÇÃO } & TOTAL \\
\hline Salário & $2.016,67 \times \mathrm{R} \$ 7,50$ & $\mathrm{R} \$ 15.125,02$ \\
\hline Descanso Semanal Remunerado & 48 dias $\times 7,3333 \times \mathrm{R} \$ 7,50$ & $\mathrm{R} \$ 2.638,80$ \\
\hline Férias & 220 horas $x \mathrm{R} \$ 7,50$ & $\mathrm{R} \$ 1.650,00$ \\
\hline Adicional de Férias & $1 / 3$ de $\mathrm{R} \$ 1.650,00$ & $\mathrm{R} \$ 550,00$ \\
\hline Feriados & 12 dias $\times 7,3333 \times \mathrm{R} \$ 7,50$ & $\mathrm{R} \$ 659,70$ \\
\hline $13^{\circ}$ salário & 220 horas $x \mathrm{R} \$ 7,50$ & $\mathrm{R} \$ 1.650,00$ \\
\hline \multicolumn{2}{|c|}{ Total das remunerações } & R\$ 22.273,52 \\
\hline \multicolumn{2}{|c|}{ ENCARGOS SOCIAIS } & TOTAL \\
\hline INSS & $8 \%$ de $\mathrm{R} \$ 22.273,52$ & $\mathrm{R} \$ 1.781,88$ \\
\hline FGTS & $8 \%$ de $\mathrm{R} \$ 22.273,52$ & $\mathrm{R} \$ 1.781,88$ \\
\hline \multicolumn{2}{|c|}{ Total dos encargos sociais } & $\mathrm{R} \$ 3.563,76$ \\
\hline \multicolumn{2}{|c|}{ OUTROS } & TOTAL \\
\hline UNIMED & $\mathrm{R} \$ 20,00 \times 12$ meses & $\mathrm{R} \$ 240,00$ \\
\hline Total de outros & & R\$ 240,00 \\
\hline Custo da Hora & $\mathrm{R} \$ 26.077,28 / 2.016,67$ & $\mathbf{R} \$ 12,93$ \\
\hline
\end{tabular}

Fonte: elaborado pelos autores

O Quadro 2, contempla os cálculos realizados com o intuito de encontrar o custo da mão de obra para cada hora trabalhada, de acordo com o salário de cada um dos colaboradores. Primeiramente, calculou-se o total da remuneração, incluindo o salário, descanso semanal remunerado, férias, adicional de férias, feriados e $13^{\circ}$ salário, o qual obteve montante de $\mathrm{R} \$ 22.273,52$. Na sequência, calculou-se o total de encargos sociais inerentes ao custo da hora do colaborador, resultando em um total de $\mathrm{R} \$ 3.563,76$. Por fim, somou-se, ao montante total encontrado, o valor de outros custos com os funcionários, correspondendo a R \$240,00. Então, a partir desses cálculos, encontrou-se um total de $\mathrm{R} \$ 26.077,28$, representando o custo de um colaborador, recebendo $\mathrm{R} \$ 7,50$ por hora trabalhada, pelo período de 2.016,67 horas* .

\footnotetext{
*2.016,67 é o valor correspondente a 275 dias disponíveis a empresa, descontando os dias de férias, de feriados e de descanso semanal remunerado.
} 
Com base no cálculo referido anteriormente, calculou-se o custo da hora para cada um dos colaboradores que participaram da execução do processo produtivo. $\mathrm{O}$ Quadro 3, a seguir, expõe os resultados encontrados.

Quadro 3 - Custo da Mão de Obra/Hora

\begin{tabular}{|l|c|c|}
\hline Colaborador & Função & Custo da Hora \\
\hline Colaborador 1 & Marceneiro & $\mathrm{R} \$ 15,83$ \\
\hline Colaborador 2 & Marceneiro & $\mathrm{R} \$ 15,83$ \\
\hline Colaborador 3 & Marceneiro & $\mathrm{R} \$ 12,93$ \\
\hline Colaborador 4 & Auxiliar de Marceneiro & $\mathrm{R} \$ 6,58$ \\
\hline Colaborador 5 & Auxiliar de Marceneiro & $\mathrm{R} \$ 6,58$ \\
\hline
\end{tabular}

Fonte: elaborado pelos autores

\subsubsection{CUSTO FIXO}

Neste componente do custo total do processo produtivo, serão consideradas três despesas fixas, as quais são efetivadas mensalmente, são elas: aluguel da metalúrgica, utilizada como anexo para realização de algumas atividades inerentes ao processo produtivo; a manutenção, que agrega os serviços prestados pelo contador como staff; e a energia elétrica utilizada para o desenvolvimento do processo produtivo. Obteve-se como custo fixo por hora trabalhada o valor apresentado no Quadro 4, exposto a seguir.

Quadro 4 - Cálculo do Custo Fixo/Hora

\begin{tabular}{|l|c|}
\hline Componente & Custo Mensal \\
\hline Aluguel da metalúrgica & $\mathrm{R} \$ 350,00$ \\
\hline Manutenção & $\mathrm{R} \$ 303,00$ \\
\hline Energia elétrica & $\mathrm{R} \$ 600,00$ \\
\hline Custo Fixo Total & $\mathrm{R} \$ 1.253,00$ \\
\hline Custo Fixo / Hora & $\mathbf{R} \$ \mathbf{5 , 6 9}$ \\
\hline
\end{tabular}

Fonte: elaborado pelos autores

Objetivando calcular o custo fixo para cada hora trabalhada no processo produtivo, somaram-se os três custos fixos que a Empresa possui mensalmente, considerando a média histórica de janeiro até setembro de 2015. A partir dessa soma, chegou-se ao valor do custo fixo mensal, o qual representou um montante de R\$ 1.253,00. Com o intuito de conhecer o custo fixo de cada hora trabalhada, dividiu-se o custo fixo mensal pelo total de horas trabalhadas no mês. $\mathrm{O}$ resultado encontrado foi de $\mathrm{R} \$ 5,69$ por hora de trabalho no processo produtivo. Com o intuito de calcular o custo de cada atividade do processo produtivo da marcenaria, será utilizada a equação a seguir, apresenta na Figura 2. 
Figura 2 - Equação do Índice do Custo da Atividade para a Marcenaria XY

ICA = (CC x Hora Máquina $)+($ CMO x Hora Homem $)+($ CF $x$ Hora $)$
Substituindo os valores determinados anteriormente tem-se:
ICA $=(\mathrm{R} \$ 0,30 \times$ Hora Máquina $)+(\mathrm{CMO} * \mathrm{x}$ Hora Homem $)+(\mathrm{R} \$ 5,69 \times$ Hora $)$
$\mathrm{ICA}=$ Índice do Custo da Atividade;
$\mathrm{CC}=$ Custo do Capital Empregado;
$\mathrm{CMO}=$ Custo da Mão de Obra;
$\mathrm{CF}=$ Custo Fixo.

Fonte: elaborado pelos autores

Na Figura 2, encontra-se a equação desenvolvida com o intuito de calcular os custos operacionais do processo produtivo da Marcenaria XY. A partir da utilização da equação desenvolvida, outras indústrias do mesmo setor terão os subsídios necessários para calcular todos os custos envolvidos com sua operação, passando a ter um controle mais rígido dos mesmos. Com a análise e acompanhamento contínuo dos índices propostos no modelo matemático, a Marcenaria XY terá a sua disposição relevantes indicadores dos seus resultados, bem como o embasamento para tomar decisões com maior velocidade e eficiência a respeito de sua produção, minimizando risco de perdas (econômicas, financeiras e de produtividade) e potencializando seus resultados e sua geração de valor.

\subsubsection{CUSTO VARIÁVEL}

Vale destacar que os custos variáveis não foram considerados no modelo proposto, pois o objetivo deste é otimizar a produtividade do processo produtivo, por meio da melhora na performance do tempo de trabalho efetivo em cada atividade do processo estudado. Sendo assim, não foram considerados os custos de matéria-prima, os custos com estocagem, os custos despendidos em logística, entre outros custos.

\section{RESULTADOS}

A Figura 3, apresentada a seguir, traz a legenda com a especificação das variáveis presentes nos fluxogramas, a qual servirá de base para análise de todos os fluxogramas expostos neste trabalho.

\footnotetext{
*O componente CMO da equação é variável, isto é, será substituída pelo valor da mão de obra correspondente a remuneração do colaborador que participou de uma atividade específica do processo produtivo.
} 
Figura 3 - Legenda explicativa para o fluxograma

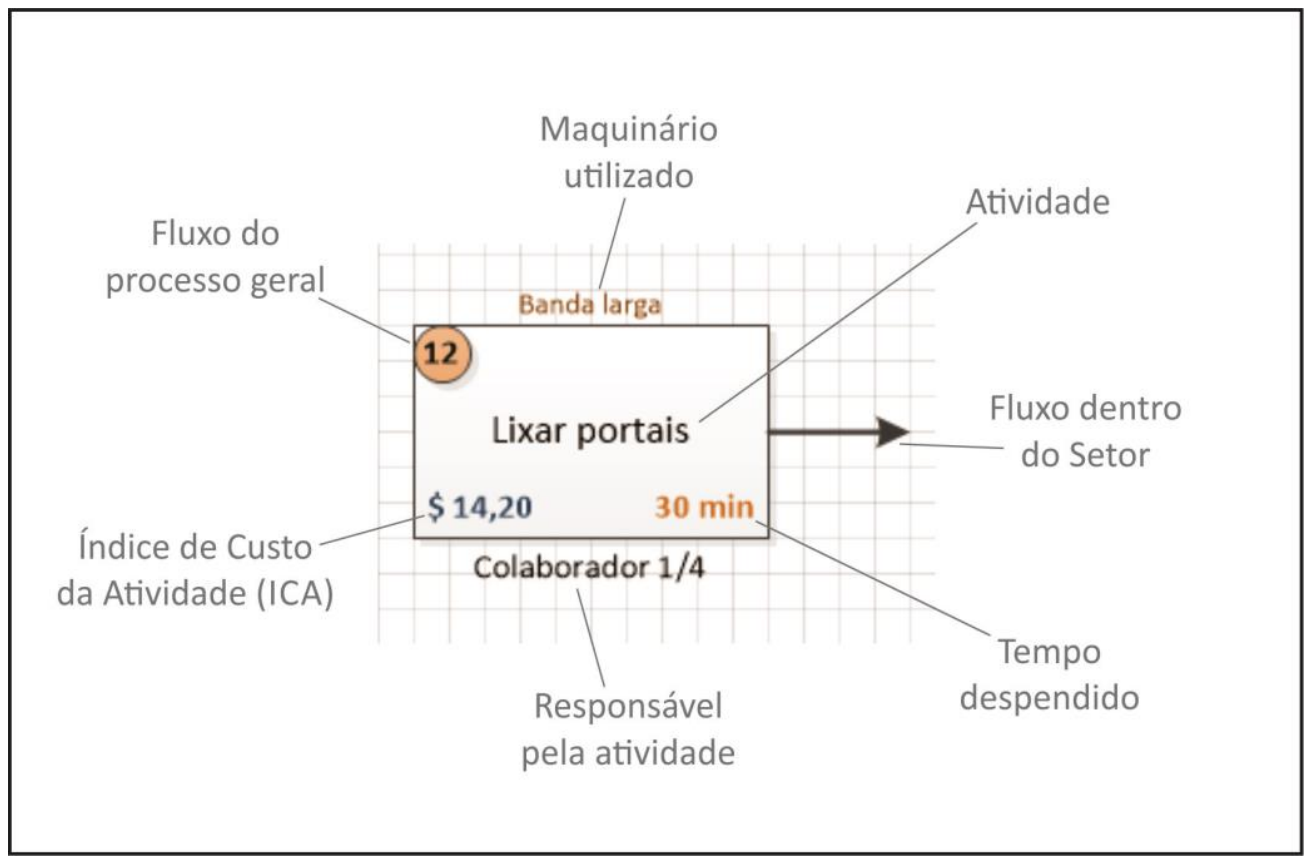

Fonte: elaborado pelos autores

Nas Figuras 4 e 5, pode-se observar o processo produtivo da Marcenaria XY contendo as sugestões de melhoria propostas pelo estudo. A partir da análise dos dados, verifica-se que o processo produtivo é dividido em cinco setores, apresentados na ordem de desenvolvimento das atividades do processo produtivo da organização estudada. Dentro de cada um dos setores são realizadas as atividades apresentadas, respeitando a ordem fixada nas figuras. 
Figura 4 - Novo Fluxograma do Processo Produtivo com Índices de Custos

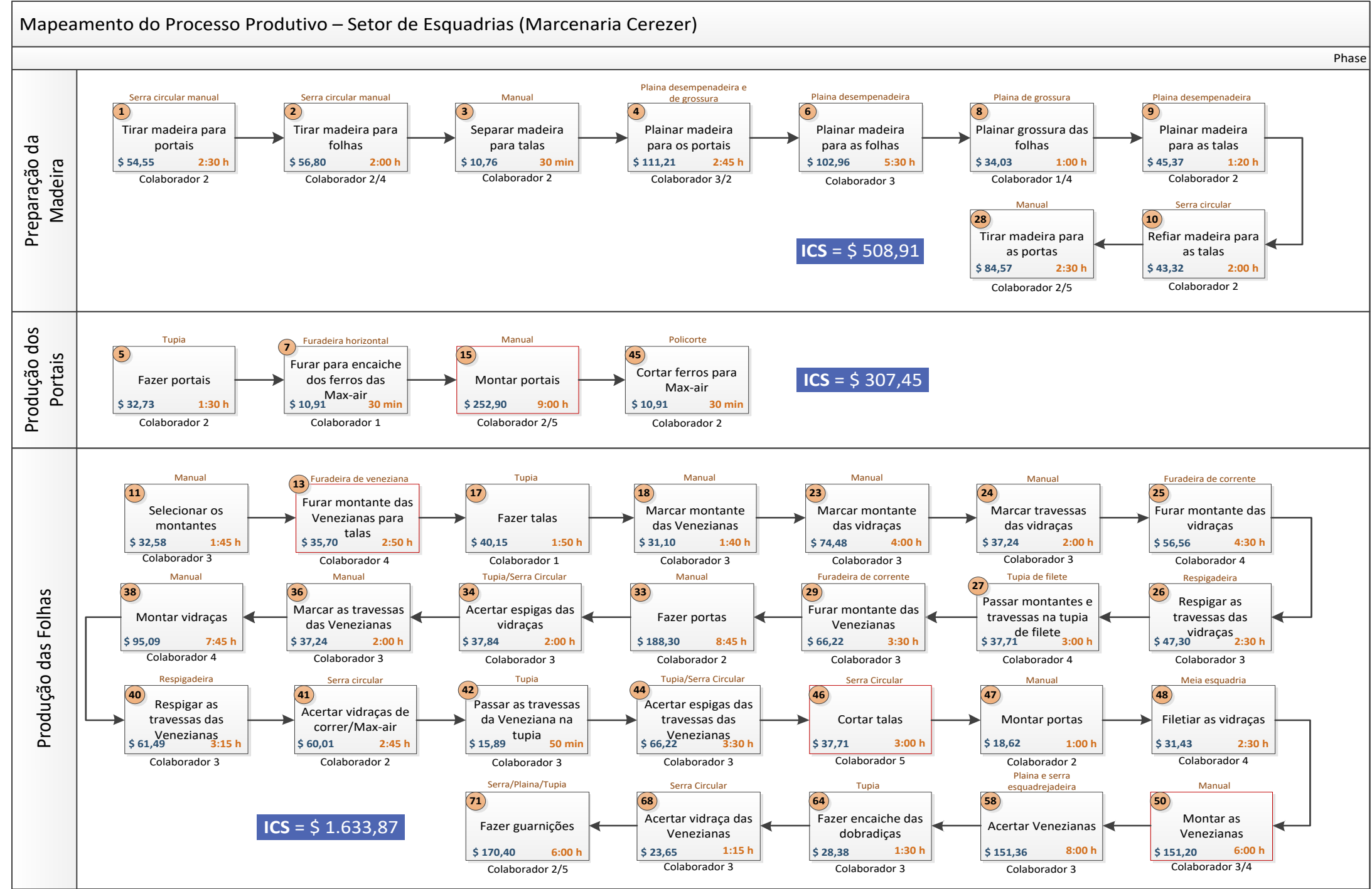

Fonte: elaborado pelos autores

Saber Humano-Revista Científica da Faculdade Antonio Meneghetti 
Figura 5 - Continuação do Novo Fluxograma do Processo Produtivo com Índices de Custos

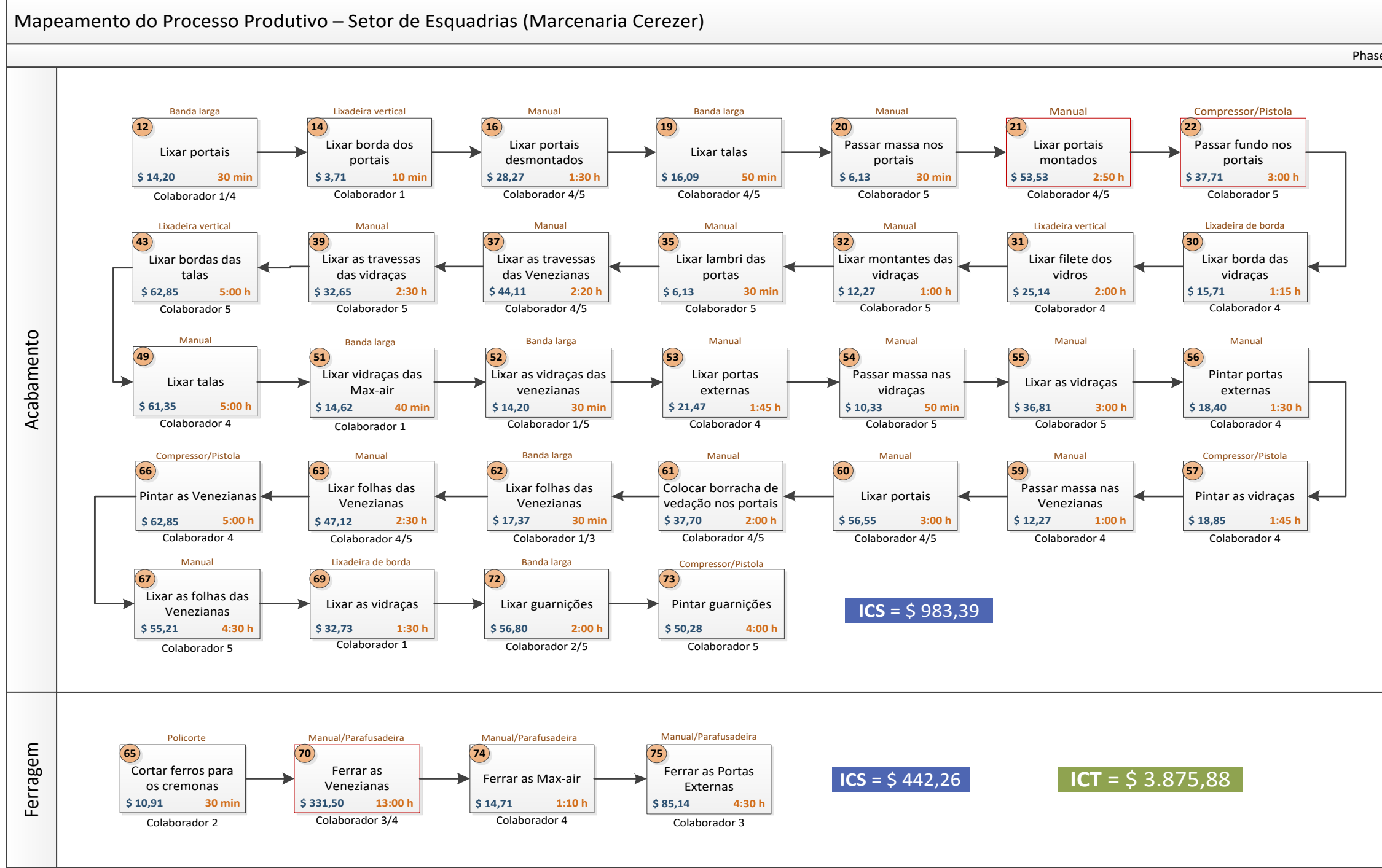

Fonte: elaborado pelos autores

Saber Humano-Revista Científica da Faculdade Antonio Meneghetti 
Ao analisar as figuras, percebe-se que existe outro fluxo de desenvolvimento das tarefas, os representados pelos círculos laranjas. Esse, por sua vez, apresenta a ordem que as atividades do processo produtivo como um todo acontecem. Como se pode observar nas figuras, esse fato implica que em alguns momentos o fluxo alterne dentre os setores existentes, como por exemplo, a atividade de número 11 ocorre no Setor de Produção das Folhas e tem sua sequência na atividade de número 12 no Setor de Acabamento e segue, posteriormente, a atividade de número 13 no Setor de Produção das Folhas novamente. A partir dessa constatação, verificam-se, preliminarmente, algumas possíveis falhas no fluxo das atividades. Ademais, ressalta-se que o processo produtivo descrito no fluxograma apresenta detalhadamente o número de colaboradores responsáveis por cada atividade, o tempo despendido para sua realização e o maquinário necessário para a execução de cada tarefa.

A partir da análise do fluxograma, apresentado nas figuras, verifica-se que o Setor de Preparação da Madeira possui poucas atividades e constatou-se que nenhuma melhoria pode ser realizada para diminuir o tempo do processo e/ou o custo inerente às atividades.

Quando analisado o setor seguinte, Setor de Produção de Portais, percebe-se que é possível adicionar um colaborador para auxiliar na montagem dos portais, atividade número 15. Com a adição desse ajudante, a atividade poderia ser realizada em 9 horas, diminuindo 5 horas e 50 minutos no processo produtivo. Além disso, seria alocado o Colaborador 5 para auxiliar na atividade, assim, o custo da atividade passaria de $\mathrm{R} \$$ 319,36 para $\mathrm{R} \$ 252,90$, uma economia de $\mathrm{R} \$ 66,46$. Esse fato se justifica, pois o valor da mão de obra do auxiliar é menos da metade do valor da mão de obra do colaborador que realiza atualmente a atividade.

No Setor de Produção das Folhas, observa-se que são necessários 26 postos de trabalho para o desenvolvimento do processo produtivo atual. A partir da análise desse setor, verificou-se que a atividade número 13 pode ser realizada por um auxiliar sem comprometer a qualidade de sua execução, diminuindo o custo da atividade em $\mathrm{R} \$$ 18,03 , a qual passará de $\mathrm{R} \$ 53,73$ para $\mathrm{R} \$ 35,70$. Ademais, destaca-se que a atividade seria desenvolvida no mesmo tempo de trabalho atual ( 2 horas e 50 minutos).

Ainda no referido setor, constata-se que a atividade número 46 (Cortar as Talas) também pode ser executada por um colaborador auxiliar, dependendo o mesmo tempo da atual estrutura para a realização da tarefa (3 horas). Esse ajuste diminuiria o custo da 
atividade de $\mathrm{R} \$ 65,46$ para $\mathrm{R} \$ 37,71$, resultando em uma economia de $\mathrm{R} \$ 27,75$ no custo desse posto de trabalho.

Além desses dois ajustes já citados, a atividade número 50 poderia ser modificada, no Setor de Produção das Folhas. A melhoria sugerida para essa atividade seria a adição de um colaborador para auxiliar na execução da tarefa, diminuindo o tempo de 11 horas e 50 minutos para 6 horas, resultando em uma economia de tempo correspondente a 5 horas e 50 minutos. Ademais, destaca-se que o custo desse posto de trabalho sofreria uma redução de $\mathrm{R} \$ 69,26$, passando de $\mathrm{R} \$ 220,46$ para $\mathrm{R} \$ 151,20$.

Com relação ao Setor de Acabamento, verifica-se que esse é composto por 32 atividades contribuindo para o desenvolvimento do processo produtivo. Como melhoria, sugere-se que no posto de trabalho 21 seja adicionado um auxiliar, reduzindo o tempo da atividade de 6 horas para 2 horas e 50 minutos. Esse ajuste fará com que o processo como um todo seja agilizado em3 horas e 10 minutos e diminuirá o custo da atividade em $\mathrm{R} \$ 20,09$.

A atividade número 22, do Setor de Acabamento, pode ser realizada com Compressor e Pistola ao invés de ser desenvolvida manualmente. Esse ajuste resultará em uma economia de $\mathrm{R} \$ 48,18$, passando de $\mathrm{R} \$ 85,89$ para $\mathrm{R} \$ 37,71$, no custo total da atividade e de 4 horas, passando de 7 horas para 3 horas, no tempo da tarefa.

Por fim, no último setor, o de Ferragem, pode receber alteração no posto de trabalho 70, o qual é responsável pela ferragem das venezianas. O ajuste que pode ser realizado é o de adicionar um colaborador para auxiliar na atividade, diminuindo o tempo total da atividade de 10 horas, passando de 23 horas para 13 horas. Além disso, haverá uma redução de $\mathrm{R}$ \$103,66 no custo da tarefa, pois o valor da mão de obra de um auxiliar é menor, quando comparado a de outro colaborador.

Quando analisado o processo produtivo como é desenvolvido atualmente, verifica-se que o somatório de todas as atividades que compõe os setores responsáveis pelo desenvolvimento do processo resulta em um custo total de $\mathrm{R} \$ 4.229,31$ e despende um total de 231 horas e 5 minutos de horas trabalhadas para realização das tarefas.

Diante desse total de horas, constatou-se que o Colaborador 3 é o que mais participa do processo, sendo responsável por 88 horas e 40 minutos de trabalho. Na sequência, aparece o Colaborador 5 com 58 horas e 10 minutos de participação no processo produtivo. Em seguida, o Colaborador 4 contribui com 52 horas e 30 minutos de trabalho para a produção de esquadrias. O Colaborador 2 participa do processo com 
50 horas e 25 minutos de trabalho. Por fim, aparece o Colaborador 1, despendendo 10 horas e 10 minutos para realização das atividades.

Com as falhas detectadas e as melhorias sugeridas para a configuração do novo fluxograma do processo produtivo da marcenaria, verifica-se que um dos benefícios será a diminuição do tempo total da produção, o qual reduzirá em 28 horas e 50 minutos, passando de 231 horas e 5 minutos para 203 horas e 45 minutos. Além disso, com os ajustes e melhorias propostas ao processo produtivo, outro benefício constatado será a redução do custo total do processo em $\mathrm{R} \$ 353,43$, passando de $\mathrm{R} \$ 4.229,31$ para $\mathrm{R} \$$ $3.875,88$.

Ademais, destaca-se que a distribuição de horas entre os colaboradores depois das alterações sugeridas apresenta-se da seguinte maneira: Colaborador 4, com 78 horas e 30 minutos; Colaborador 5, com 71 horas e 30 minutos; Colaborador 3, com 69 horas; Colaborador 2, com 47 horas e 50 minutos; e por fim, o Colaborador 1, com 7 horas. Vale destacar que os Colaboradores 1 e 2 possui menos horas trabalhas para desenvolvimento do processo produtivo que os demais funcionários, pois esses dois são a equipe responsável pela colocação e instalação das esquadrias prontas na residência do cliente, despendendo mais horas para essa atividade.

Diante dos resultados, conclui-se que, quando comparados os valores referentes ao custo das atividades, há uma diminuição expressiva, correspondendo a 8,35\% no custo total do processo. Além disso, quando analisados os valores referentes aos tempos despendidos para a realização das tarefas, verifica-se que com as melhorias sugeridas haverá uma redução de, aproximadamente, $12 \%$ no tempo de desenvolvimento do processo produtivo da marcenaria como um todo.

Os resultados referidos implicam diretamente na capacidade de produção da Empresa, isto é, na quantidade de obras que poderão ser produzidas no período de 12 meses. Atualmente, o setor tem a capacidade de produzir, em média, 21 obras por ano, além dos outros serviços realizados pela Empresa, os quais não foram mapeados por serem produtos e serviços complementares, como por exemplo, decks, revestimentos de escada, entre outros. A partir das melhorias sugeridas para o fluxograma do processo, espera-se que a capacidade de produção das obras seja aumentada em 12\%, representando 2,5 obras a mais no mesmo período analisado. 


\section{CONSIDERAÇÕES FINAIS}

O presente trabalho teve como objetivo geral propor um modelo produtivo para indústrias de esquadrias, com o intuito de otimizar seus resultados financeiros e econômicos, além de identificar possíveis melhorias. Visando responder aos objetivos fixados, optou-se por utilizar as diretrizes da ferramenta BPM (Business Process Management). Para tanto, primeiramente, realizaram-se observações diretas do processo produtivo da Empresa em seu estágio atual. Nessa etapa foram anotados, no software de análise de dados Microsoft Excel 2010, aspectos inerentes ao desenvolvimento da produção como: a atividade, a data de realização, os horários de início e término da tarefa, o responsável e o maquinário necessários para sua execução.

Em seguida, essas informações foram transferidas para a forma de fluxograma, no software de elaboração de fluxogramas Microsoft Visio 2010, a fim de simular o fluxo do processo produtivo mapeado. Depois de elaborado o fluxograma do processo produtivo da Marcenaria XY, procedeu-se à análise e identificação de falhas no mesmo, conforme proposto pelo BPM. Essa etapa consistiu em verificar, a partir das informações coletadas, quais atividades estavam sendo desenvolvidas de acordo com o processo produtivo considerado ideal e quais necessitavam de ajustes para adequação à produção. Além disso, foram identificados pontos falhos e sugeridas melhorias para as atividades. Por fim, foi aplicado o modelo matemático desenvolvido neste estudo para o processo produtivo da Marcenaria XY, tendo como resultado os Índices de Custos operacionais inerentes à produção.

A partir da análise realizada, detectaram-se 7 atividades com gargalos em sua execução, dentre as 75 tarefas realizadas para o desenvolvimento do processo produtivo como um todo. Diante dos resultados encontrados, conclui-se que, com os ajustes e as melhorias propostos para o fluxograma do processo produtivo, os objetivos geral e específicos traçados para o presente trabalho foram concretizados, salientando a relevância do estudo para a Empresa pesquisada, bem como para as demais indústrias de esquadrias.

Destaca-se, como primeira contribuição deste trabalho, a ampliação do conhecimento estratégico da Empresa. Por meio do mapeamento de seu processo produtivo, a marcenaria terá maior controle sobre sua produção, analisando e decidindo de maneira consciente, ou seja, ciente dos aspectos e do nível em que serão impactados a partir das decisões tomadas. 
Na sequência, ressalta-se a agilidade que será propiciada à produção que terá seu tempo reduzido em aproximadamente $12 \%$. Essa melhoria propicia o aumento da capacidade de produção, produzindo 2,5 obras a mais no mesmo período de tempo, no mesmo espaço físico e com os mesmo colaboradores de que dispõe atualmente.

Além disso, destaca-se que, a partir do modelo matemático desenvolvido, o custo de algumas das atividades realizadas no processo foi reduzido, depois de ajustadas com a troca de colaboradores e/ou diminuição do tempo da tarefa, em $\mathrm{R} \$ 353,43$ no custo total da produção de cada obra. Esse resultado contribui para a potencialização dos resultados financeiros e geração de valor da Empresa.

Por fim, a partir dos resultados encontrados neste trabalho, verifica-se a possibilidade de replicá-lo em outras práticas consideradas importantes para a organização como, por exemplo, o controle de estoque, o processo de venda e o processo de compra de materiais, com o intuito de conhecer melhor o processo e sua contribuição para a Empresa, detectar os índices de custos de cada prática e propor as melhorias necessárias para alinhar o processo com as estratégias da organização em estudo.

\section{REFERÊNCIAS}

ADAIR, Charlene B. MURRAY, Bruce A. Revolução total dos processos. São Paulo: Nobel, 1996.

ALBUQUERQUE, A.; ROCHA, P. Sincronismo Organizacional: como alinhar a estratégia, os processos e as pessoas. São Paulo, Ed. Saraiva, 2006.

\section{BARNETT, M. W. Modeling and simulation in business process management.} Gensym Corporation, 2003.

BRODBECK, A. F. et al. Uma Metodologia para Implementação da Gestão por Processos em Organizações Públicas. Rev. Adm. UFSM, Santa Maria, v. 9, n. 4, p. 699-720, 2016.

CAPOTE, G. BPM Para Todos: Uma Visão Geral, Abrangente, Objetiva e Esclarecedora sobre Gerenciamento de Processos de Negócio | BPM. 2012

DATZ, D. et al. Mapeamento de processos como instrumento de apoio à implementação do custeio baseado em atividades nas organizações. XXIV Encontro Nac. de Eng. de Produção. Santa Catarina: Florianópolis, nov., 2004.

DEBEVOISE, T. Business Process Management with a Business Rules Approach: Implementing the Service Oriented Architecture. Roanoke, Virginia, Business Knowledge Architects, 2005. 
DIXON, J. Hype Cycle for Business Process Managemen. Disponível em:

<http://www. gartner.com>. Publicado em 27 jul. 2012. Acessado em 13 out. 2017.

GIL, A. C. Como elaborar projetos de pesquisa. São Paulo: Atlas, 2002.

GONÇALVES, J. E. L. As empresas são grandes coleções de processos. RAE, v. 40, n. 1, p. 6-19, jan./mar. 2000.

HAMMER, M.; CHAMPY, J. Reengenharia: o caminho para a mudança. 29. ed. Rio de Janeiro: Campus, 1994.

LEE, R. G.; DALE, B. G. Business process management: a review and evaluation.

Business Process Management Journal, v. 4, n. 3, p. 214-225, 1998.

OULD, M. A. Business process management: a rigorous approach. England: BCS, 2005.

RICHARDSON, R. J. Pesquisa social: métodos e técnicas. São Paulo: Atlas, 1999.

ROESCH, Sylvia Maria Azevedo. Projetos de estágio do curso de administração: guia para pesquisas, projetos, estágios e trabalhos de conclusão de curso. São Paulo: Atlas, 1996.

ROSSÉS, G. F. et al. A gestão por processos e as atividades intensivas em conhecimento: um estudo na indústria de bebidas. Rev. Adm. UFSM, Santa Maria, v. 10, n. 3, p. 386-401, 2017.

SANTIS, S. H. da S. et al. A metodologia Business Process Modeling (BPM) para implantação do sistema de gestão da qualidade. Educação, Gestão e Sociedade: Revista da Faculdade Eça de Queiros, n. 7, p. 1-20, set., 2012.

SMART, P. A. et al. Understanding Business Process Management: Implications for Theory and Practice. British Journal of Management, v. 20, p. 491-507, 2009.

VILLELA, C. S. S. Mapeamento de Processos como Ferramenta de Reestruturação e Aprendizado Organizacional. Dissertação de Mestrado pelo Programa de PósGraduação em Engenharia de Produção, Universidade Federal de Santa Catarina, Florianópolis, 2000.

YIN, Robert K. Estudo de caso: planejamento e métodos. Porto Alegre: Bookman, 2005. 